\title{
Resistência antimicrobiana em Enterococcus faecalis e Enterococcus faecium isolados de carcaças de frango ${ }^{1}$
}

\author{
Ana Claudia F. Borges de Campos², Nara R. Souza², Patrícia H.C. da Silva² \\ e Ângela P. Santana ${ }^{2 *}$
}

\begin{abstract}
Campos A.C.F.B., Souza N.R., Silva P.H.C. \& Santana A.P. 2013 [Antimicrobial Resistance of Enterococcus faecalis and Enterococcus faecium isolated from poultry carcasses.] Resistência antimicrobiana em Enterococcus faecalis e Enteroccus faecium isolados de carcaças de frango. Pesquisa Veterinária Brasileira 33(5):575-580. Laboratório de Microbiologia de Alimentos, Faculdade de Agronomia e Medicina Veterinária, Universidade de Brasília, Campus Darcy Ribeiro, ICC Sul, ASS sala 128/10, Asa Norte, Brasília, DF 70910900, Brazil. E-mail: patvet@unb.br

The aim of this study was to isolate and analyze the antimicrobial profile resistance of Enterococcus from cooled and frozen poultry carcasses commercialized at the Federal District area, detecting the antimicrobial resistance genes and identifying Enterococcus faecalis and Enterococcus faecium by polymerase chain reaction. One hundred poultry carcasses were analyzed and 50 strains of Enterococcus spp. were isolated, of which $42 \%$ were E. faecalis and $2 \%$ E. faecium. The antimicrobial susceptibility test showed that all isolates were resistant to at least one antibiotic; $90,47 \%$ of E. faecalis, $100 \%$ of E. faecium and $82,14 \%$ of Enterococcus spp. were resistant to Tetracycline; 80,95\% of E. faecalis and 35,71\% of Enterococcus spp. strains were resistant to Erythromycin; 39,28\% of Enterococcus spp. and $23,80 \%$ of $E$. faecalis to Ciprofloxacin, and $28,57 \%$ of E. faecalis were resistant to Chloramphenicol. There were detected $\operatorname{erm}(B), \operatorname{vanC}-1$, aph(3')-llla, $\operatorname{ant}(6)-l a, \operatorname{vanB}, \operatorname{van} A, \operatorname{aac}\left(6^{\prime}\right)$ -le-aph(2")-la, $\operatorname{erm}(A)$ and $\operatorname{tet}(M)$ resistance genes, the last one most often verified. The results might suggest problems for public health due the high resistance, since these microorganisms have ability to transmit genes for antimicrobial resistance to others in the intestinal tract of humans and animals. Thus, the use of these drugs for clinical treatment could be hindered.
\end{abstract}

INDEX TERMS: Enterococcus faecalis, Enteroccus faecium, antimicrobial resistance, tetracycline, chloramphenicol, poultry carcasses.

RESUMO.- 0 objetivo deste trabalho foi realizar o isolamento e analisar o perfil de resistência antimicrobiana de Enterococcus de carcaças de frango resfriadas e congeladas comercializadas no Distrito Federal, detectando genes de resistência antimicrobiana e identificando as espécies Enterococcus faecalis e Enterococcus faecium por reação polimerase em cadeia. Foram analisadas 100 carcaças de frangos, das quais foram isoladas 50 cepas de Enterococcus spp., sendo $42 \%$ de E. faecalis e $2 \%$ de E. faecium. 0 teste de susceptibilidade antimicrobiana demonstrou que todas as cepas isoladas

\footnotetext{
${ }^{1}$ Recebido em 28 de novembro de 2012.

Aceito para publicação em 11 de março de 2013.

${ }^{2}$ Laboratório de Microbiologia de Alimentos (LAMAL), Faculdade de Agronomia e Medicina Veterinária, Universidade de Brasília (UnB), Campus Darcy Ribeiro, ICC Sul ASS 128/10, Brasília, DF 70910-900, Brasil. *Autor para correspondência: patvet@unb.br
}

apresentaram resistência a pelo menos um antimicrobiano, dos quais $90,47 \%$ das cepas de $E$. faecalis, $100 \%$ das cepas de E. Faecium e $82,14 \%$ dos Enterococcus spp. apresentaram resistência à Tetraciclina; 80,95\% das cepas de E. faecalis e $35,71 \%$ das cepas de Enterococcus spp. foram resistentes à Eritromicina; 39,28\% dos Enterococcus spp. e 23,80\% dos E. faecalis à Ciprofloxacina e 28,57\% dos E. faecalis apresentaram resistência ao Cloranfenicol. Foram detectados os genes de resistência antimicrobiana $\operatorname{erm}(B), \operatorname{vanC}-1, \operatorname{aph}\left(3^{\prime}\right)-11 l a$, ant(6)-la, vanB, vanA, aac(6')-le-aph(2")-la, erm(A) e tet(M) este último mais frequente. Estes resultados sugerem sérios problemas para a Saúde Pública, uma vez que esses microrganismos podem possuir a capacidade de transmitir genes de resistência antimicrobiana para outros microrganismos presentes na microbiota intestinal de humanos e animais, podendo inviabilizar o uso destas drogas para tratamentos clínicos. 
TERMOS DE INDEXAÇÃO: Enterococcus faecalis, Enteroccus faecium, resistência antimicrobiana, tetraciclina, cloranfenicol, carcaças de frango.

\section{INTRODUÇÃO}

Os Enterococcus spp. compõem a microbiota intestinal de seres humanos e animais saudáveis e estão amplamente distribuídos no ambiente (Biavasco et al. 2007, Casal et al. 2009, López et al. 2009, Riboldi et al. 2009). As duas espécies mais importantes, E. faecium e E. faecalis, estão frequentemente implicadas em infecções em animais e humanos imunocomprometidos, como bacteremia, septicemia, infecções do trato urinário, infecções de feridas, meningites e endocardites (Cauwerts et al. 2007, Gama 2008, Kense et al. 2011, Zou et al. 2011). Sabe-se que os Enterococcus spp. são propensos a sofrer seleção a cada administração de antimicrobiano, levando à formação de um reservatório animal de Enterococcus spp. resistentes, que podem infectar os seres humanos tanto por contato direto com animais como através da ingestão de alimentos de origem animal (Kaszanyitzky et al. 2007, Oliveira et al. 2010, Vignaroli et al. 2011). No trato gastrintestinal, os genes de resistência adquiridos podem ser transferidos por elementos móveis de DNA, tanto para outros da espécie como outros agentes zoonóticos, mesmo que em testes de antibiograma os Enterococcus não apresentem resistência (Bogaard et al. 2002, Cauwerts et al. 2007). No contexto do Brasil, como um dos maiores produtores exportadores mundiais de carnes de aves, é de notório conhecimento que, no sistema de criação de frangos, drogas antimicrobianas podem ser utilizadas como agentes terapêuticos e/ou promotores de crescimento (Oliveira et al. 2010). No intuito de se verificar uma possível relação, a Agência Nacional de Vigilância Sanitária - ANVISA realizou um estudo preliminar e de âmbito nacional, unicamente em carcaças congeladas de frangos, em que se verificou o monitoramento da prevalência e da resistência bacteriana para Enterococcus e Salmonella (Brasil 2008b), sem maiores detalhamentos do número de amostras analisadas por região do país.

No Brasil, há poucos levantamentos a respeito da ocorrência de cepas de Enterococcus em alimentos de origem animal, tendo sido os relatos clínicos os mais publicados, em que se analisam cepas isoladas de pacientes humanos em hospitais. No contexto internacional, a Dinamarca se destaca em relação à realização de levantamentos de ocorrência desta bactéria em carnes e outros alimentos de origem animal, bem como a análise de resistência antimicrobiana e detecção de genes de resistência, em trabalhos conduzidos por Aarestrup et al. (2000). Diante do exposto, o presente trabalho teve por objetivo pesquisar cepas de Enterococcus spp. resistentes isoladas de carcaças resfriadas e congeladas de frango comercializadas na região do Distrito Federal.

\section{MATERIAL E MÉTODOS}

Origem das amostras e isolamento microbiológico. Foram adquiridas 100 amostras de carcaças de frango, sendo 54 carcaças resfriadas e 46 congeladas, de diversas marcas comercializadas em 20 estabelecimentos comerciais localizados no Distrito
Federal no período de Junho a Dezembro de 2010. As amostras foram adquiridas simulando uma situação real de compra pelo consumidor, sendo, portanto um estudo observacional (Pereira 1995), onde uma unidade amostral adquirida era composta por uma carcaça inteira, com embalagem íntegra, sem qualquer sinal de violação, e dentro do prazo de validade. As amostras foram transportadas até o Laboratório de Microbiologia de Alimentos (LAMAL) da UnB em caixas isotérmicas e posteriormente acondicionadas em refrigerador a $4^{\circ} \mathrm{C}$, para em seguida proceder ao isolamento microbiológico.

A metodologia utilizada para o isolamento de Enterococcus spp. foi a descrita por López et al. (2009). Para cada colônia isolada foi feito a coloração de Gram, o teste de catalase e hidrólise enzimática da L-pyrrolidonyl-beta-naphtylamide (PYRTEST PROBAC do Brasil ${ }^{\circledR}$ ). As colônias com morfologia de cocos Gram positivos, negativos para catalase e positivos para PYR foram submetidas à realização do antibiograma.

Identificação por PCR das espécies Enterococcus faecalis e E. faecium e teste de suscetibilidade antimicrobiana. Para a identificação das espécies E. faecalis e E. faecium foi realizada uma PCR-multiplex de colônia utilizando os primers $d d l_{E \text {. faecalis }}$ e $d d l_{E \text {.fa- }}$. descritos por Titze-de-Almeida et al. (2004), em que amplificam fragmentos de $941 \mathrm{bp}$ e $550 \mathrm{bp}$, respectivamente. A programação para amplificação utilizada foi descrita por estes mesmos autores. Foi feita análise de Qui-quadrado $(\mathrm{p}=0,05)$ para verificar a relação entre tipos de carcaças (congeladas e resfriadas) e as espécies identificadas.

Para cada colônia isolada foi realizado o teste de antibiograma, e as bases farmacológicas analisadas foram: Ampicilina $(10 \mu \mathrm{g})$, Vancomicina $(30 \mu \mathrm{g})$, Teicoplanina $(30 \mu \mathrm{g})$, Gentamicina $(10 \mu \mathrm{g})$, Eritromicina $(15 \mu \mathrm{g})$, Ciprofloxacina $(5 \mu \mathrm{g})$, Enrofloxacina $(5 \mu \mathrm{g})$, Tetraciclina $(30 \mu \mathrm{g})$, Cloranfenicol $(30 \mu \mathrm{g})$, Ceftazidima $(30 \mu \mathrm{g})$ e Cefalotina $(30 \mu \mathrm{g})$, todos da marca BIO-RAD ${ }^{\circledR}$. 0 método utilizado foi o de disco de difusão, conforme recomendado por National Committee for Clinical Laboratory Standards (NCCLS, 2003).

Detecção de genes de resistência antimicrobiana através da PCR. Para a realização da detecção dos genes de resistência por PCR, foram utilizadas colônias isoladas conforme descrito por Titze-de-Almeida et al. (2004). Para a identificação dos genes de resistência aos antimicrobianos, foram utilizados os primers vanA, vanB, vanC-1 e vanC-2/3 para Vancomicina; os primers ant(6)-Ia, aac(6')-Ie-aph(2')-Ia e aph(3')-IIIa para Aminoglicosídeos; os primers erm(A), $\operatorname{erm}(B), \operatorname{erm}(C)$ para Macrolídeos; e o primer tet(M) para Tetraciclina (Torres et al., 2003). As condições para a realização da PCR-multiplex para detecção dos genes de resistência à Vancomicina foram as mesmas utilizadas na diferenciação das espécies E. faecium e E. faecalis. Para a identificação de genes de resistência à Macrolídeos e Aminoglicosídeos foi utilizado o protocolo descrito por Angot et al. (2000), com aumento na temperatura de anelamento de $47^{\circ} \mathrm{C}$ para $52^{\circ} \mathrm{C}$, com objetivo de minimizar o aparecimento de reações inespecíficas. Foram definidos 35 ciclos de $94^{\circ} \mathrm{C}$ por $5 \min , 94^{\circ} \mathrm{C}$ por 30 s, $52^{\circ} \mathrm{C}$ por $45 \mathrm{~s}, 72^{\circ} \mathrm{C}$ por 1 min e uma extensão final de $72^{\circ} \mathrm{C}$ por $10 \mathrm{~min}$. A detecção de genes de resistência para Tetraciclina foi realizada segundo protocolo descrito por Rahman et al. (2008), composto por 30 ciclos de $94^{\circ} \mathrm{C}$ por $1 \mathrm{~min}, 56^{\circ} \mathrm{C}$ por $30 \mathrm{~s}, 72^{\circ} \mathrm{C}$ por 1 min e uma extensão final de $72^{\circ} \mathrm{C}$ por $5 \mathrm{~min}$.

\section{RESULTADOS E DISCUSSÃO}

Isolamento microbiológico em amostras de frango resfriado e congelado comercializados no Distrito Federal

Das amostras de carcaças de frango analisadas, 29 resfriadas $(53,7 \%)$ e 21 congeladas $(45,65 \%)$ foram positivas para a pesquisa de Enterococcus spp., totalizando 50 
(50\%) carcaças positivas. Este resultado foi similar aos observados por Fracalanzza et al. (2007) e Leite \& Franco (2009), que verificaram $56,8 \%$ e $37 \%$ para a presença de Enterococcus spp. em carne de frango do Estado do Rio de Janeiro, respectivamente. Riboldi et al. (2009), em diversos tipos de alimentos, relataram $54,6 \%$ de presença de Enterococcus spp. na região Sul do Brasil. Em pesquisa efetuada em todo o Brasil, detectou-se a presença de Enterococcus spp. em 98,7\% das carcaças de frango congeladas (Brasil 2008b). Na aplicação do teste do Qui-quadrado, não houve diferença significativa $(p>0,05)$ entre os tipos de carcaça (resfriada e congelada) para a frequência de presença de Enterococcus spp.

Identificação por PCR das espécies Enterococcus faecalis, E. faecium e realização do teste de resistência antimicrobiana

Das 50 cepas de Enterococcus spp. isoladas, 21 (42\%) foram identificadas como E. faecalis e uma (2\%) como $E$. faecium, sendo que as outras 28 (56\%) foram consideradas como Enterococcus spp. por obterem resultado negativo na PCR para identificação das duas espécies pesquisadas. 0 resultado da eletroforese da PCR pode ser visualizado na Figura 1. Estes resultados foram similares aos verificados por Fracalanzza et al. (2007), em que detectaram-se 85 (50.9\%) cepas de E. faecalis e cinco (3\%) de E. faecium em amostras de carne de frangos do Rio de Janeiro. Riboldi et al. (2009) detectaram 27 (48,21\%) cepas de E. faecalis, 23 (41\%) de E. faecium e seis $(10,7 \%)$ de Enterococcus spp. isoladas de diversos alimentos na região Sul do Brasil. Na pesquisa do PREBAF (Brasil 2008b), foi verificada a presença de $61,4 \%$ de E. faecalis e $2,2 \%$ de E. faecium. Chan et al. (2008), que pesquisaram Enterococcus spp. em amostras de fezes de frangos e amostras de água provenientes

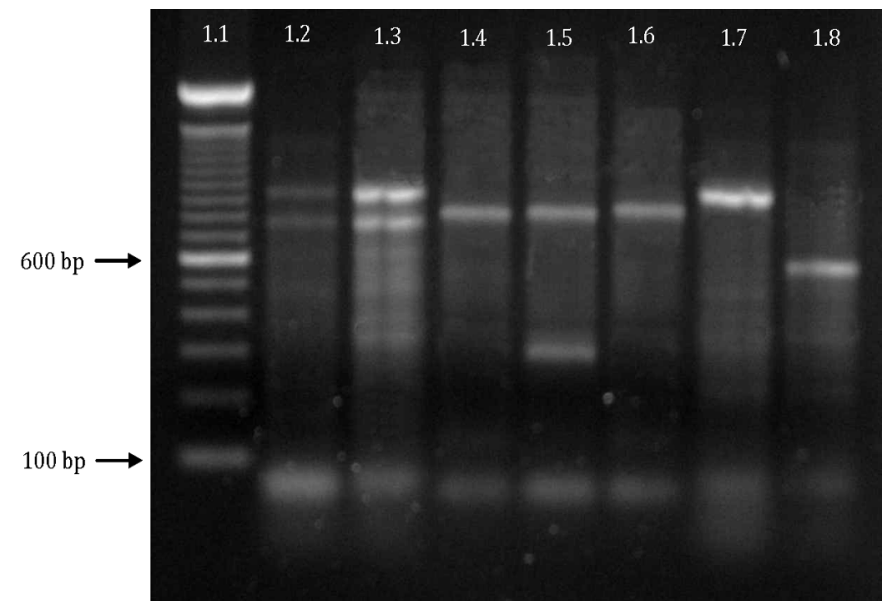

Fig.1. PCR múltipla para identificação das espécies Emterococcus faecalis, E. faecium e detecção dos genes de resistência vanA, vanB, vanC-1. 1.1) Marcador DNA ladder 100bp; 1.2 e 1.3) fragmento de 941 bp da espécie E. faecalis e fragmento de 732 bp do gene vanA; 1.4 e 1.6) fragmento de 822 bp do gene vanC$1 ; 1.5)$ fragmento de 822 bp do gene van $C$-1 e fragmento de 300 bp do gene $v a n B$; 1.7) fragmento de 941 bp da espécie $E$. faecalis; 1.8) fragmento de $550 \mathrm{bp}$ da espécie E. faecium. Visualização em gel de agarose a 1,5\% com concentração de 5 mg/ ml de brometo de etídio.
Quadro 1. Teste de resistência antimicrobiana realizados em 50 cepas de Enterococos isoladas de carcaças de frango resfriadas e congeladas comercializados no Distrito Federal

\begin{tabular}{|c|c|c|c|c|c|c|c|c|c|}
\hline \multirow[t]{2}{*}{$\begin{array}{l}\text { Agente Anti- } \\
\text { microbiano }\end{array}$} & \multicolumn{3}{|c|}{$\begin{array}{l}\text { E. faecalis } \\
(\mathrm{n}=21)\end{array}$} & \multicolumn{3}{|c|}{$\begin{array}{l}\text { E. faecium } \\
(n=1)\end{array}$} & \multicolumn{3}{|c|}{$\begin{array}{c}\text { Enterococcus spp. } \\
(\mathrm{n}=28)\end{array}$} \\
\hline & $\mathrm{S}(\%)$ & $\mathrm{I}(\%)$ & $\mathrm{R}(\%)$ & $\mathrm{S}(\%)$ & $\mathrm{I}(\%)$ & $\mathrm{R}(\%)$ & $\mathrm{S}(\%)$ & $\mathrm{I}(\%)$ & $\mathrm{R}(\%)$ \\
\hline AM & 100 & 0 & 0 & 100 & 0 & 0 & 89,28 & 0 & 10,71 \\
\hline VAN & 42,85 & 57,14 & 0 & 100 & 0 & 0 & 100 & 0 & 0 \\
\hline TEC & 100 & 0 & 0 & 100 & 0 & 0 & 100 & 0 & 0 \\
\hline GEN & 85,71 & 0 & 14,28 & 100 & 0 & 0 & 100 & 0 & 0 \\
\hline ERI & 9,52 & 9,52 & 80,95 & 0 & 100 & 0 & 21,42 & 42,85 & 35,71 \\
\hline CIP & 38,09 & 38,09 & 23,80 & 0 & 100 & 0 & 28,57 & 32,14 & 39,28 \\
\hline ENR & 14,28 & 66,66 & 19,04 & 0 & 100 & 0 & 14,28 & 42,85 & 42,85 \\
\hline TET & 4,76 & 4,76 & 90,47 & 0 & 0 & 100 & 17,85 & 0 & 82,14 \\
\hline CLO & 33,33 & 38,09 & 28,57 & 100 & 0 & 0 & 85,71 & 14,28 & 0 \\
\hline CAZ & 0 & 0 & 100 & 0 & 100 & 0 & 0 & 3,57 & 96,42 \\
\hline CFL & 4,76 & 42,85 & 52,38 & 100 & 0 & 0 & 14,28 & 42,85 & 42,85 \\
\hline
\end{tabular}

$\overline{\mathrm{AM}}=$ ampicilina; $\mathrm{VAN}=$ vancomicina; $\mathrm{TEC}=$ teicoplanina; $\mathrm{GEN}=$ gentami cina; $\mathrm{ERI}$ = eritromicina; $\mathrm{CIP}$ = ciprofloxacina; $\mathrm{ENR}$ = enrofloxacina; TET = tetraciclina; $\mathrm{CLO}=$ cloranfenicol; $\mathrm{CAZ}=$ ceftazidima; $\mathrm{CFL}=$ cefalotina. Perfil de resistência: $\mathrm{S}$ = suscetível; $\mathrm{I}$ = intermediário; $\mathrm{R}$ = resistente.

de criação de frangos, em Kelantan na Malásia, observaram $47(47 \%)$ cepas de E. faecalis e $22(22 \%)$ de E. faecium.

Com relação ao teste de resistência antimicrobiana, os resultados encontrados estão dispostos no Quadro 1. Todas as cepas (100\%) de Enterococcus isoladas foram resistentes a pelo menos um antimicrobiano testado. Sobre a resistência à Ceftazidima e à Cefalotina, Hammerum, Lester \& Heuer (2010) e Kasimoglu-Dogru, Gencay \& Ayaz (2010) relataram que os Enterococcus spp. possuem resistência intrínseca a esta classe de antimicrobiano. Observaram-se $90,47 \%$ dos E. faecalis, $100 \%$ dos E. faecium e $82,14 \%$ dos Enterococcus spp. resistentes à Tetraciclina e $80,95 \%$ dos E. faecalis e 35,71\% dos Enterococcus spp. resistentes à Eritromicina, sendo similares aos resultados encontrados por Busani et al. (2004) em carne de frango na Itália, com 95\% dos E. faecium e $81 \%$ dos E. faecalis resistentes a Tetraciclina e $55 \%$ de E. faecalis resistentes a Eritromicina, não observando o mesmo em cepas de E. faecium. Kasimoglu-Dogru, Gencay \& Ayaz (2010), na região de Ancara na Turquia, constataram resistência à Tetraciclina em $98 \%$ dos $E$. faecium e $100 \%$ dos E. faecalis e à Eritromicina em $90 \%$ dos E. faecium e $94 \%$ dos E. faecalis, isolados de pele de pescoço de frango. O PREBAF (Brasil 2008b) relatou resistência à Tetraciclina em 91,9\% dos Enterococcus spp. e à Eritromicina em $89,2 \%$ na região do Distrito Federal. Entretanto, frequências menores já foram observadas em Enterococcus spp. isolados de carne de frango (Fracalanzza et al. 2007). Importante ressaltar que o uso deste antimicrobiano na alimentação de frangos é proibido no Brasil desde 2009 (Brasil 2009). Com relação aos Macrolídeos, a Tilosina e a Espiramicina são de uso permitido como promotores de crescimento (Brasil 2008a) e o alto nível de resistência à Eritromicina provavelmente está relacionado a ampla utilização dessa classe de antimicrobiano em criação animal (Aslam et al. 2010, Zou et al. 2011).

Foram observados $23,80 \%$ dos E. faecalis e $39,28 \%$ dos Enterococcus spp. resistentes à Ciprofloxacina. Em Portugal, 27,5\% dos Enterococcus isolados do ambiente de criação de frangos apresentaram resistência a este antimicrobiano 
(Costa et al. 2010). Busani et al. (2004) relataram 51\% dos E. faecium e $10 \%$ dos E. faecalis resistentes à Ciprofloxacina em carne de frango na Itália. Neste trabalho, não foi observada resistência à Ciprofloxacina em cepas de E. faecium, sendo que há descrições de cepas com resistência intermediária à Quinolonas (Klare et al. 2003, Aslam et al. 2010).

Foram observados $28,57 \%$ de E. faecalis resistentes ao Cloranfenicol. Entretanto, não houve isolados de E. faecium resistentes. No Brasil, o uso de Cloranfenicol em animais destinados a alimentação foi banido em 2003 (Brasil 2003). Kasimoglu-Dogru, Gencay \& Ayaz (2010) relataram resistência ao Cloranfenicol em 38\% dos E. faecalis e em $53 \%$ de E. faecium isolados de pele de pescoço de frango na Turquia, onde é proibido, não descartando o uso ilegal deste antimicrobiano ou a possibilidade da resistência de se prolongar na população mesmo após a remoção da pressão seletiva.

Observaram-se 57,14\% de $E$. faecalis com resistência intermediária à Vancomicina, sendo que os demais isolados foram sensíveis. Riboldi et al. (2009) encontraram resistência à Vancomicina em 3,5\% dos E. faecalis e resistência intermediária de 7,4\% dos E. faecalis isolados de alimentos. Entretanto, Fracalanzza et al. (2007) não verificaram resistência em amostras de carne de frango e leite em E. faecalis e E. faecium. Segundo Oliveira et al. (2010), resultados de sensibilidade à Vancomicina apoiam a eficiência da proibição do uso desse Glicopeptídeo. Entretanto, testes de resistência devem ser mantidos na rotina, por ainda se observar relatos de resistência intermediária a esse antimicrobiano.

Todos os isolados testados de E. faecalis e E. faecium apresentaram sensibilidade à Ampicilina e 14,28\% de E. faecalis foram resistentes à Gentamicina. Riboldi et al. (2009) relataram resistência à Ampicilina de $11,1 \%$ das cepas de $E$. faecalis isolados de alimentos diversos e resistência à Gentamicina em $22,2 \%$ de E. faecalis e $13 \%$ em E. faecium. Frequências maiores foram relatadas por Busani et al. (2004), que encontraram resistência à Ampicilina em $20 \%$ dos $E$. faecium e $22 \%$ dos E. faecalis isoladas de carne de frango; e $10 \%$ dos E. faecium e $11 \%$ dos E. faecalis demonstraram resistência à Gentamicina. A Anvisa (Brasil 2008b) relatou em Enterococcus spp. a resistência à Gentamicina em $27 \%$ em carcaças de frango congeladas no Distrito Federal e todas as amostras apresentaram sensibilidade à Ampicilina, embora não seja mencionado o número de amostras analisadas nesta região.

\section{Detecção de genes de resistência antimicrobiana}

Os resultados da detecção dos genes de resistência antimicrobiana nas 50 cepas de Enterococcus isoladas das carcaças de frangos encontram-se no Quadro 2 e as bandas de identificação dos genes podem ser visualizadas nas Figuras 1 e 2. Observaram-se 93\% dos Enterococcus spp. resistentes à Tetraciclina com o gene tet( $M)$, sendo similar aos resultados obtidos por Gama (2008) na cidade de Porto Alegre, em que $90 \%$ das cepas de Enterococcus spp. resistentes à Tetraciclina, isolados de alimentos e de processos infecciosos, possuíam o gene tet(M). Poeta et al. (2005) em Portugal, relataram que o gene tet( $M)$ foi encontrado em todas as cepas resistentes à Tetraciclina em Enterococos
Quadro 2. Resultado da PCR para detecção dos genes de resistência das cepas de Enteroccocus faecalis, E. faecium e Enterococcus spp. isoladas de carcaças de frango resfriadas e congeladas

\begin{tabular}{|c|c|c|}
\hline Espécie (n) & Gene & $\begin{array}{c}\text { Número de cepas } \\
\text { positivas (\%) }\end{array}$ \\
\hline \multirow[t]{7}{*}{ E. faecalis (21) } & $\operatorname{tet}(M)$ & $17(81 \%)$ \\
\hline & $\operatorname{erm}(B)$ & $16(76,2 \%)$ \\
\hline & $\operatorname{aph}\left(3^{\prime}\right)-11 l a$ & $9(42,9 \%)$ \\
\hline & $\operatorname{van} C-1$ & $8(38 \%)$ \\
\hline & ant(6)-la & $8(38 \%)$ \\
\hline & $\operatorname{van} A$ & $4(19 \%)$ \\
\hline & $\operatorname{aac}\left(6^{\prime}\right)-\operatorname{le}-\operatorname{aph}\left(2^{\prime \prime}\right)-l a$ & $3(14,3 \%)$ \\
\hline E. faecium (1) & $\operatorname{tet}(M)$ & $1(100 \%)$ \\
\hline \multirow{7}{*}{ Enterococcus spp. (28) } & $\operatorname{tet}(M)$ & $24(85,7 \%)$ \\
\hline & $\operatorname{van} C-1$ & $15(53,57 \%)$ \\
\hline & $\operatorname{erm}(B)$ & $10(35,71 \%)$ \\
\hline & $\operatorname{van} B$ & $7(25 \%)$ \\
\hline & $\operatorname{aph}\left(3^{\prime}\right)-11 l a$ & 7 (25\%) \\
\hline & ant(6)-la & $6(21,42 \%)$ \\
\hline & $\operatorname{erm}(A)$ & $1(3,57 \%)$ \\
\hline
\end{tabular}

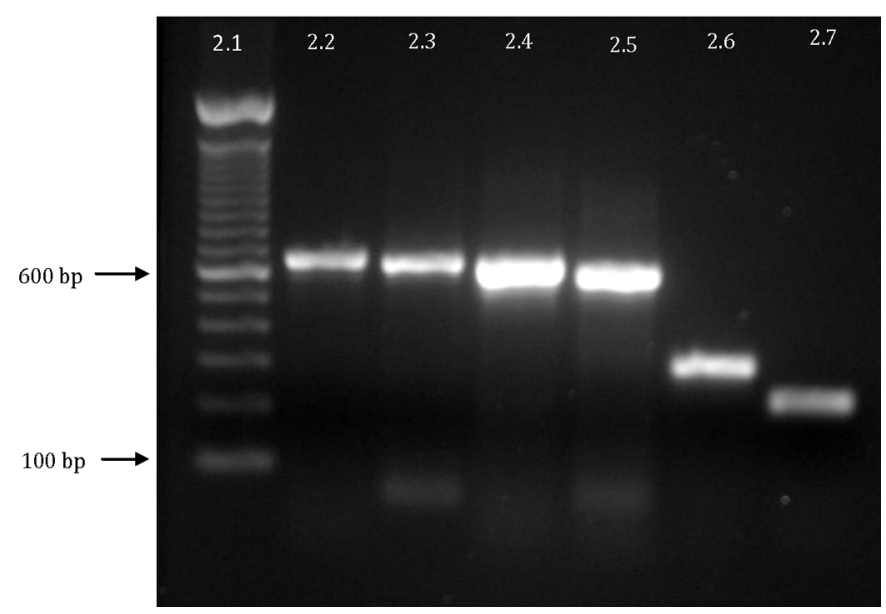

Fig.2. PCR uniplex para identificação dos genes de resistência antimicrobiana tet(M), erm(A), erm(B), aph(3')-IIIa, ant(6)-Ia e aac(6')-Ie-aph(2')-Ia. 2.1) Marcador DNA ladder 100bp; 2.2) fragmento de $696 \mathrm{bp}$ do gene tet (M); 2.3) fragmento de 645 bp do gene erm (A); 2.4) fragmento de 639 do gene erm (B); 2.5) fragmento de 597 bp do gene ant(6)-Ia; 2.6) fragmento de 292 bp do gene aph(3')-IIIa; 2.7) fragmento de 220 bp do gene $\operatorname{aac}\left(6^{\prime}\right)-I e-a p h\left(2^{\prime \prime}\right)-I a$. Visualização em gel de agarose a 1,5\% com concentração de $1 \%$ de brometo de etídio.

isolados de animais selvagens. Agersø, Pedersen \& Aarestrup (2006) na Dinamarca, observaram que o gene tet(M) foi detectado em $95 \%$ dos E. faecium e E. faecalis isolados de humanos, suínos e frangos de corte.

Com relação à presença de genes de resistência a Macrolídeos, 22 (85\%) amostras de Enterococcus resistentes à Eritromicina no antibiograma apresentaram o gene erm(B), sendo similar ao estudo efetuado por López et al. (2009) na Espanha, que demonstrou que todas as 12 cepas isoladas de Enterococcus spp. que apresentaram resistência à Eritromicina foram positivas para os gene $\operatorname{erm}(B)$, e cinco cepas apresentaram o gene erm(A). Zou et al. (2011) efetuaram uma pesquisa em E. faecalis isolados de suínos na China e observaram que 54 cepas apresentaram o gene $\operatorname{erm}(B)$ e 37 cepas demostraram possuir o gene $\operatorname{erm}(A)$. As- 
lam et al. (2010) descreve a presença do gene $\operatorname{erm}(B)$ em $50 \%$ dos E. faecium, já os genes $\operatorname{erm}(A)$ e $\operatorname{erm}(C)$ não foram encontrados em nenhum isolado.

Neste estudo, no que diz respeito à presença de genes de resistência aos Aminoglicosídeos, todas as amostras de E. faecalis resistentes à Gentamicina no teste de susceptibilidade antimicrobiana apresentaram o gene aac $\left(6^{\prime}\right)-I e$ -aph(2")-Ia. Ainda, 38\% dos E. faecalis e 21,42\% de Enterococcus spp. apresentaram o gene ant(6)-la; e 42,9\% de E. faecalis e $25 \%$ Enterococcus spp. apresentaram o gene aph(3')-IIIa. Similarmente, Gama (2008) relatou que 100\% das amostras resistentes à Gentamicina apresentaram o gene aac(6')-Ie-aph(2")-Ia. López et al. (2009) relataram que das 11 cepas isoladas de Enterococcus spp. resistentes à Estreptomicina, sete foram positivas para o gene ant(6)-la. 0 gene aph(3')-llla foi detectado em cinco cepas isoladas, de um total de seis, de E. gallinarum resistentes à Canamicina. Uma cepa positiva para o gene vanC-1 demonstrou alto nível de resistência à Gentamicina no teste de susceptibilidade antimicrobiana e esta apresentou o gene aac(6')-Ie-aph(2")-Ia. Poeta et al. (2005), em uma pesquisa em Portugal em animais selvagens, relataram que o gene aac(6')-Ie-aph(2")-Ia foi observado em duas cepas de E. faecalis com alto nível de resistência à Gentamicina, e três cepas demonstraram resistência antimicrobiana à Canamicina e também apresentaram o gene aph(3')-Illa.

Observaram-se a presença de 15 isolados de Enterococcus spp. e oito de $E$. faecalis com gene vanC-1, sete de $E n$ terococcus spp. com gene vanB e quatro de E. faecalis com gene vanA. Xavier (2007), em uma pesquisa de isolamento de Enterococcus spp. de amostras de fezes de frangos realizada no Distrito Federal, relataram o gene vanC-1 em $13 \%$ das cepas isoladas e nenhuma cepa foi positiva para os genes vanA e vanB. Biavasco et al. (2007) relataram que $\mathrm{o}$ achado de vanA em E. faecalis em carne sugere um envolvimento de alimentos na propagação de Enterococcus spp. resistentes aos Glicopeptídeos para seres humanos. Agers $\varnothing$ et al. (2008) relatam que E. faecalis resistente à Vancomicina presente em carne de peru pode ser uma fonte de transmissão deste microrganismo resistente à Vancomicina para o intestino saudável de humanos.

Cauwerts et al. (2007) concluíram que Enterococcus isolados de aves carregando genes de resistência antimicrobiana podem não apenas transferir estes genes para outros microrganismos, possivelmente patogênicos, mas podem representar um perigo à saúde humana no caso de transferência desses genes para bactérias zoonóticas. Além disso, Enterococcus spp. podem ser transferidos, direta ou indiretamente, para o homem, onde eles podem ser capazes de causar doenças ou dispersar seus genes de resistência antimicrobiana entre a microbiota gastrointestinal. Riboldi et al. (2009) comentam que uma das razões que podem explicar o surgimento da resistência antimicrobiana em Enterococcus spp. isolados de alimentos pode estar relacionado ao uso massivo de antibióticos na agricultura, uma vez que estudos têm demonstrado que o mesmo gene de resistência foi encontrado simultaneamente em alimentos e pacientes. Investigações experimentais mostraram que o plasmídeo de resistência $p A M \beta 1$ foi transferido entre $E$. faecalis, E. faecium e Lactobacillus reuteri no trato digestivo de camundongos e transferido entre cepas de L. curvatus em salsichas fermentadas, corroborando com a hipótese de que Enterococcus resistentes podem contaminar os alimentos, entrar no trato gastrointestinal humano e colonizar os seres humanos e/ou passar seus genes de resistência para bactérias comensais presentes no trato intestinal humano, situação de risco para a saúde pública (Riboldi et al. 2009).

\section{CONCLUSÃO}

Os resultados encontrados alertam para o fato da presença de Enterococcus spp. multirresistentes em carcaças de frango no Distrito Federal com possibilidade de transmissão de genes de resistência antimicrobiana para outros microrganismos em humanos e animais, o que pode acarretar sérios problemas para a Saúde Pública, uma vez que inviabiliza o uso destes medicamentos em tratamentos clínicos. São necessários mais estudos para uma melhor compreensão do assunto e para identificar a real fonte de contaminação destes alimentos por esta bactéria, bem como a origem da resistência antimicrobiana.

Agradecimentos.- À Coordenação de Aperfeiçoamento de Pessoal de Nível Superior (CAPES), pela concessão de bolsa de mestrado.

\section{REFERÊNCIAS}

Aarestrup F.M., Agerso Y., Gerner-Smidt P., Madsen M. \& Jensen L.B. 2000. Comparison of antimicrobial resistance phenotypes and resistance genes in Enterococcus faecalis and Enterococcus faecium from humans in the community, broilers and pigs in Denmark. Diagn. Micr. Infec. Dis. 37:127-137.

Agersø Y., Pedersen A.G. \& Aarestrup F.M. 2006. Identification of Tn5397-like and Tn916-like transposons and diversity of the tetracycline resistance gene tet $(M)$ in enterococci from humans, pigs and poultry. J. Antimicrob. Chemoth. 57:832-839.

Agersø Y., Lester C.H., Porsbo L.J., Ørsted I., Emborg H-D., Olsen K.E.P., Jensen L.B., Heuer O.E., Frimodt-Møller N., Aarestrup F.M. \& Hammerum A.M. 2008. Vancomycin-resistant Enterococcus faecalis isolates from a Danish patient and two healthy human volunteers are possibly related to isolates from imported turkey meat. J. Antimicrob. Chemoth. 62:844845.

Angot P., Vergnaud M., AuzouM. \& Leclercq R. 2000. Macrolide resistance phenotypes and genotypes in French clinical isolates of Streptococcus pneumoniae. Eur. J. Clin. Microbil. 19:755-758.

Aslam M., Diarra M.S., Service C. \& Rempel H. 2010. Characterization of antimicrobial resistance in Enterococcus spp. recovered from a commercial beef processing plant. Foodborne Pathog. Dis. 7:235-241.

Biavasco F., Foglia G., Paoletti C., Zandri G., Magi G., Guaglianone E., Sundsfjord A., Pruzzo C., Donelli G. \& Facinelli B. 2007. VanA-type enterococci from humans, animals, and food: species distribution, population structure, Tn1546 typing and location, and virulence determinants. Appl. Environ. Microb. 73:3307-3319.

Bogaard A.E., Willems R., London N., Top J. \& Stobberingh E.E. 2002. Antibiotic resistance of faecal enterococci in poutry, poultry farmers and poultry slaughterers. J. Antimicrob. Chemoth. 49(3):497-505.

Brasil 2003. MAPA, Instrução Normativa no 9 publicada em 27 de junho de 2003

Brasil 2008a. MAPA, Tabela de aditivos antimicrobianos, anticoccidianos e agonistas com uso autorizado na Alimentação animal. Atualizado em 3 de dezembro de 2008.

Brasil 2008b. Relatório do monitoramento da prevalência e do perfil de suscetibilidade aos antimicrobianos em Enterococos e Salmonelas 
isolados de carcaças de frango congeladas comercializadas no Brasil. Programa Nacional de Monitoramento da Prevalência e da Resistência Bacteriana em Frango - PREBAF. Ministério da Saúde, Agência Nacional de Vigilância Sanitária (Anvisa).

Brasil 2009. MAPA, Instrução Normativa no 26 publicada em 9 de julho de 2009.

Busani L., Grosso M.D., Paladini C., Graziani C., Pantosti A., Biavasco F. \& Caprioli A. 2004. Antimicrobial susceptibility of vancomycin-susceptible and -resistant enterococci isolated in Italy from raw meat products, farm animals, and human infections. Int. J. Food Microbiol. 97:17-22.

Casal M.M., Cause M., Solis F., Rodriz F. \& Casal M. 2009. Investigación de las resistências a antimicrobianos en Enterococcus faecalis. Revta Esp. Quimioter. 22:117-119.

Cauwerts K., Decostere A., De Graef E.M., Haesebrouck F. \& Pasmans F. 2007. High prevalence of tetracycline resistance in Enterococcus isolates from broilers carrying the erm (B) gene. Avian Pathol. 36:395-399.

Chan Y.Y., Nasir M.H.B.A., Yahaya M.A.B., Salleh N.M.A.B., Dan A.D.B.M., Musa A.M.B. \& Ravichandran M. 2008. Low prevalence of vancomycinand bifunctional aminoglycoside-resistant enterococci isolated from poultry farms in Malaysia. Int. J. Food Microbiol. 122:221-226.

Costa P.M., Bica A., Vaz-Pires P. \& Bernardo F. 2010. Changes in antimicrobial resistance among faecal enterococci isolated from growing broilers prophylactically medicated with three commercial antimicrobials. Prev. Vet. Med. 93:71-76.

Fracalanzza S.A.P., Scheidegger E.M.D., Santos P.F. dos, Leite P.C. \& Teixeira L.M. 2007. Antimicrobial resistance profiles of enterococci isolated from poultry meat and pasteurized milk in Rio de Janeiro, Brazil. Mem. Inst. Oswaldo Cruz 102:853-859.

Gama B.A. 2008. Análise da resistência antimicrobiana e de genes de virulência de Enterococcus spp. Dissertação de Mestrado em Ciências, Centro de Biotecnologia, Universidade Federal do Rio Grande do Sul, Porto Alegre, RS. 73p.

Hammerum A.M., Lester C.H. \& Heuer O.E. 2010. Antimicrobial-resistant Enterococci in animals and meat: a human health hazard? Foodborne Pathog. Dis. 7:1137-1146.

Kasimoglu-Dogru A., Gencay Y.E. \& Ayaz N.D. 2010. Prevalence and antibiotic resistance profiles of Enterococcus species in chicken at slaughter level: absence of vanA and vanB genes in E. faecalis and E. faecium. Res. Vet. Sci. 89:153-158.

Kaszanyitzky E.J., Tenk M., Ghidán A., Fehérvári G.Y. \& Papp M. 2007. Antimicrobial susceptibility of enterococci strains isolated from slaughter animals on the data of Hungarian resistance monitoring system from 2001 to 2004. Int. J. Food Microbiol. 115:119-123.

Kense M.J. \& Landman W.J.M. 2011. Enterococcus cecorum infections in broiler breeders and their offspring: molecular epidemiology. Avian Pathol. 40(6):603-612.

Klare I., Konstabel C., Badstübner D., Werner G. \& Witte W. 2003. Occurrence and spread of antibiotic resistances in Enterococcus faecium. Int. J. Food Microbiol. 88:269-290.
Leite A.M.O. de \& Franco R.M. 2009. Enumeração e identificação bioquímica de Enterococcus spp. em carne de frango comercializada no Rio de Janeiro. Hig. Aliment. 22:155-159.

López M., Sáenz Y., Rojo-Bezares B., Martínez S., del Campo R., Ruiz-Larrea F., Zarazaga M. \& Torres C. 2009. Detection of vanA and vanB2-containing enterococci from food samples in Spain, including Enterococcus faecium strains of CC17 and the new singleton ST425. Int. J. Food Microbiol. 133:172-178.

NCCLS 2003. Performance Standards for Antimicrobial Disk Susceptibility Tests; Approved Standard. $8^{\text {th }}$ ed. Document M2-A8 [ISBN 1-56238485-6], National Committee for Clinical Laboratory Standards (NCCLS), Wayne, Pennsylvania, USA.

Oliveira M., Santos V., Fernandes A., Bernardo F. \& Vilela C.L. 2010. Antimicrobial resistance and in vitro biofilm-forming ability of enterococci from intensive and extensive farming broilers. Poultry Sci. 89:10651069.

Pereira M.G. 1995. Epidemiologia: teoria e prática. Ed. Guanabara Koogan, Rio de Janeiro. 583p.

Poeta P., Costa D., Sáenz Y., Klibi N., Ruiz-Larrea F., Rodrigues J. \& Torres C. 2005. Characterization of antibiotic resistance genes and virulence factors in faecal Enterococci of wild animals in Portugal. J. Vet. Med. B, Infect. Dis. Vet. Public Health 52:396-402.

Rahman M.H., Nonaka L., Tago R. \& Suzuki S. 2008. Occurrence of two genotypes of tetracycline (TC) resistance gene test (M) in the TC-resistant bacteria in marine sediments of Japan. Environ. Sci. Technol. 42:50555061.

Riboldi G.P., Frazzon J., Azevedo P.A. \& Frazzon A.P.G. 2009. Antimicrobial resistance profile of Enterococcus spp. isolated from food in Southern Brazil. Braz. J. Microbiol. 40:125-128.

Titze-de-Almeida R., Filho M.R., Nogueira C.A., Rodrigues I.P., Filho J.E., Nascimento R.S. do, Ferreira R.F., Moraes L.M.P., Boelens H., Van Belkum A. \& Felipe M.S.S. 2004. Molecular epidemiology and antimicrobial susceptibility of Enterococci recovered from Brazilian intensive care units. Braz. J. Infect. Dis. 8:197-205.

Torres C., Tenorio C., Portillo A., García M., Martínez C., Del Campo R., Ruiz-Larrea F. \& Zarazaga M. 2003. Intestinal colonization by vanA- or vanB2-containing Enterococcal isolates of healthy animals in Spain. Microb. Drug Resist. 9:47-52.

Vignaroli C., Zandri G., Aquilanti L., Pasquaroli S. \& Biavasco F. 2011. Multidrug-resistant Enterococci in meat and faeces and co-transfer of resistance from an Enterococcus durans to a human Enterococcus faecium. Curr. Microbiol. 62:1438-1447.

Xavier D.B. 2007. Prevalência e variabilidade genética de Enterococos com resistência à vancomicina, isolados de frangos caipiras de regiões do Distrito Federal. Dissertação de Mestrado em Ciências Agrárias, Faculdade de Agronomia e Medicina Veterinária, Universidade de Brasília, Brasília, DF. 33p.

Zou L.K., Wang H.N., Zeng B., Li J.N., Li X.T., Zhang A.Y., Zhou Y.S., Yang X., Xu C.W. \& Xia Q.Q. 2011. Erythromycin resistance and virulence genes in Enterococcus faecalis from swine in China. New Microbiol. 34:73-80. 